\title{
A Comparison of Pain and Operation Time in Children Undergoing a Tonsillectomy using Different Energy Doses of Bipolar Cautery
}

\author{
Ayhan Kars ${ }^{1}$ (D), Fatih Bingöl2 (D), Korhan Kılıç3 (D) \\ ${ }^{1}$ Kastamonu University, Faculty of Medicine, Department of Otorhinolaryngology, Head and Neck Surgery, Kastamonu, Turkey \\ ${ }^{2}$ Nigde Omer Halisdemir University Training and Research Hospital, Clinic of Otorhinolaryngology, Nigde, Turkey \\ ${ }^{3}$ Ataturk University, Faculty of Medicine, Department of Otorhinolaryngology, Head and Neck Surgery, Erzurum, Turkey
}

ORCID ID: A.K. 0000-0003-4580-315X; F.B. 0000-0001-8260-0349; K.K. 0000-0001-6048-034X

Citation: Kars A, Bingol F, Kilic K. A comparison of pain and operation time in children undergoing a tonsillectomy using different energy doses of bipolar cautery. Tr-ENT 2021;31(1):6-9. https://doi.org/10.26650/Tr-ENT.2021.30092

\begin{abstract}
Objective: The aim of the study is to compare the operative time and degree of post-operative pain in children who underwent a tonsillectomy using different energy doses of bipolar cautery and to specify the most appropriate energy dose.

Materials and Methods: Patients included in the study were allocated to three groups with 20 in each and each group underwent the operation with 20, 30 and 40 watt energy doses of bipolar cautery. Operative time was recorded for each patient. The Wong-Baker FACES pain rating Scale (WBS) was used in the post-operative period for each patient and the pain severity of the patients was evaluated at post-operative $30^{\text {th }}$ min, $1^{\text {st }}$, $6^{\text {th }}, 24^{\text {th }}$ hours and $10^{\text {th }}$ day. The operative times and pain severity of the patients were compared thereafter.

Results: A significant difference was not detected between the groups in which 20,30 and 40 watt bipolar cautery was used ( $p>0.05$ ). A significant difference was not detected between groups with regard to pain scores at post-operative $30^{\text {th }} \mathrm{min}, 1^{\text {st }}, 6^{\text {th }}, 24^{\text {th }}$ hour and $10^{\text {th }}$ day ( $p>0.05$ ).

Conclusion: We have compared groups with regard to post-operative pain and operative time according to energy dose of bipolar cautery and detected no statistically significant difference in tonsillectomies conducted with different energy doses. Therefore we consider that energy dose should be as low as possible in tonsillectomies conducted with bipolar cautery.
\end{abstract}

Keywords: Bipolar cautery, child, operation time, postoperative pain, tonsillectomy

\section{INTRODUCTION}

The tonsillectomy is one of the most common surgeries performed in otorhinolaryngology clinics, especially in children with recurrent tonsillitis and tonsil hypertrophy (1-3). Although there are different surgical techniques for carrying out a tonsillectomy, the determinant factor on which technique to perform is the incidence of complications that may occur during and after the surgery (1). Cold dissection, monopolar and bipolar cautery dissection, harmonic scalpel tonsillectomy and coblation tonsillectomy are the methods used in tonsillectomy (2). The common purpose of all these techniques is to reduce the complications of surgery, shorten the operation time, and increase the comfort and safety of the patient (4). Among these methods, bipolar cautery is the most commonly used
(1). Bipolar cautery is an important technique in terms of less intraoperative blood loss and shorter operation time $(5,6)$.

Postoperative pain is the most worrying problem in patients undergoing tonsillectomy (2). Pains usually lasting longer than 1 week can be seen (3). There are pharmacological and surgical approaches for pain reduction. ${ }^{(2)}$ Bipolar cautery can cause tissue damage due to high heat that can reach $400-600^{\circ} \mathrm{C}(2$, $3)$. Therefore, it is important to perform the operation with a low energy dose. There are conflicting results in terms of postoperative pain in previous studies conducted using low and high energy (3).

The aim of this study was to compare the operation time and the degree of postoperative pain in children having undergone

Corresponding Author: Ayhan Kars E-mail: drakars25@hotmail.com

Submitted: 22.01.2021・ Revision Requested: 31.05.2021 • Last Revision Received: 04.06.2021 • Accepted: 06.06.2021

This work is licensed under Creative Commons Attribution-NonCommercial 4.0 International License. 
tonsillectomy using different energy doses of bipolar cautery and to determine the most appropriate energy dose.

\section{PATIENTS AND METHODS}

For this prospectively planned study, approval was obtained from Ataturk University Faculty of Medicine Clinical Research Ethics Committee with number of B.30.2.ATA.0.01.00 / 58. 60 children aged between 3-15 years who were evaluated in Erzurum Regional Training and Research Hospital in Otorhinolaryngology Clinic and who decided to undergo tonsillectomy between the dates of February 2018 - May 2018 were included in the study. Written informed consent was obtained from the parents of the patients for the operation.

Patients with known bleeding disorder, chronic disease, suspected hematological malignancy, peritonsillar abscess history, acute upper respiratory tract infection, drug allergy and acute tonsillitis were excluded from the study. Patients were questioned as to their use of aspirin. Preoperative whole blood count, prothrombin time (PT) and activated thromboplastin time (aPTT) were tested routinely. The patients were divided into three groups of 20 patients and the groups were operated on using 20,30, and 40 watts of bipolar cautery (Covidien ValleyLab Force Fx Electrosurgical Generator, Instant Response $^{\mathrm{TM}}$ Technology, USA), respectively. The operations were performed under endotracheal general anesthesia. $3-5 \mathrm{mg} / \mathrm{kg}$ sodium thiopental and $0.6 \mathrm{mg} / \mathrm{kg}$ rocuronium bromide were used for anesthesia induction. Anaesthesia was maintained with $1-2 \%$ sevoflurane after intubation. Intravenoz (iv) $1 \mathrm{mg} /$ $\mathrm{kg}$ methylprednisolone was given prior to surgery.

A bilateral tonsillectomy was performed using a bipolar cautery device with the dissection method. A bipolar cautery device was used for intraoperative and postoperative bleeding control and the surgery was completed. Intraoperative $10 \mathrm{mg} / \mathrm{kg}$ iv paracetamol was given to patients. $30 \mathrm{mg} / \mathrm{kg}$ amoxicillin/ clavulanic acid and $10 \mathrm{mg} / \mathrm{kg}$ paracetamol were given through orally and initiated at the postoperative $2^{\text {nd }}$ hour and maintained every 8 hours for 1 week. The patients were discharged from the hospital at the postoperative $24^{\text {th }}$ hour and a check was performed on the postoperative $10^{\text {th }}$ day. The operations were performed by 2 surgeons using the same method on 10 patients in each group. The operation time was recorded for each patient. The pain status of the children was evaluated by using the "Wong-Baker Faces Pain Rating Scale" (Figure 1) for each patient after the surgery at the $30^{\text {th }}$ minute, $1^{\text {st }}, 6^{\text {th }}, 24^{\text {th }}$ hours and on the $10^{\text {th }}$ day. In the Wong-Baker Scale, according to the children's facial expression 0 'no pain' and 5 'most severe' were recorded as pain conditions (7).

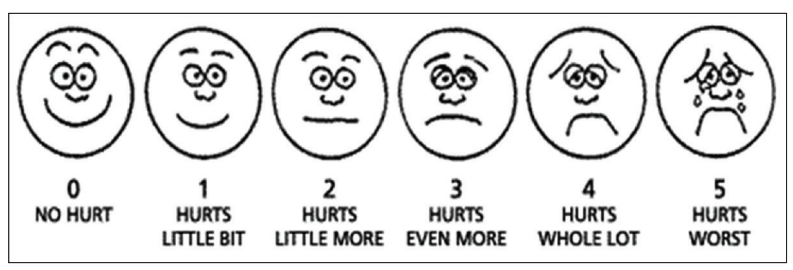

Figure 1: Wong-Baker Faces Pain Rating Scale

\section{Statistical analysis}

SPSS 17.0 (IBM Corporation, Chicago, NY, USA) program was used for statistical analysis. The distribution of the data was checked by the Shapiro-Wilk test. The one-way ANOVA test and post hoc Tukey test were used for the analysis of the quantitative data while the Chi-square test was used for the analysis of the categorical data. For all analyses, $p<0.05$ was considered statistically significant.

\section{RESULTS}

Of 60 patients included in the study, 31 were male and 29 were female. The ages of the patients in the groups where 20 watts, 30 watts and 40 watts bipolar cautery were used for the operation were $6.3 \pm 2.3,7.3 \pm 2.8$ and $7.5 \pm 3.7$, respectively. There was no significant difference in terms of age and gender between the three groups ( $p>0.05)$. When the operation time was examined, the mean operation time using 20 watts, 30 watts or 40 watts bipolar cautery was determined to be $11.9 \pm 4.4,12.3 \pm 4.7$ and $11.9 \pm 3.8$, respectively. It was observed that use of 20 watts, 30 watts or 40 watts bipolar cautery did not make a difference significantly in terms of operation time $(p>0.05)$.

When the postoperative pain scores of the patients were examined, according to the Wong Baker scale, the pain scores of the patients who had undergone surgery with 20 watts, 30 watts and 40 watts of bipolar cautery at the postoperative $30^{\text {th }}$ minute were determined to be $2 \pm 1.1,1.8 \pm 0.8,1.7 \pm 0.8$, respectively. It was determined to be $1.1 \pm 0.9,1.4 \pm 0.9,1 \pm 0.9$ at the postoperative 1st hour, respectively. It was found to be $0.3 \pm 0.5,0.7 \pm 0.5,0.4 \pm 0.6$ at the postoperative $6^{\text {th }}$ hour, respectively. It was detected to be $0.1 \pm 0.3,0.3 \pm 0.5,0.2 \pm 0.5$ at the postoperative $24^{\text {th }}$ hour, respectively. It was determined to be 0 for all degrees at the postoperative $10^{\text {th }}$ day. There was no significant difference between the three groups in terms of pain scores of the postoperative $30^{\text {th }}$ minute, $1^{\text {st }}$ hour, $6^{\text {th }}$ hour, $24^{\text {th }}$ hour and $10^{\text {th }}$ day $(p>0.05)$ (Table 1$)$.

Table 1: Comparison of postoperative pain conditions according to the Wong Baker Scale

\begin{tabular}{llllll}
\hline & $\mathbf{3 0}^{\text {th }} \mathbf{m i n}$ & $\mathbf{1}^{\text {st }}$ hour & $\mathbf{6}^{\text {th }}$ hour & $\mathbf{2 4}^{\text {th }}$ hour & $\mathbf{1 0}^{\text {th }}$ day \\
\hline 20 watt & $2 \pm 1.1$ & $1.1 \pm 0.9$ & $0.3 \pm 0.5$ & $0.1 \pm 0.3$ & 0 \\
30 watt & $1.8 \pm 0.8$ & $1.4 \pm 0.9$ & $0.7 \pm 0.5$ & $0.3 \pm 0.5$ & 0 \\
40 watt & $1.7 \pm 0.8$ & $1 \pm 0.9$ & $0.4 \pm 0.6$ & $0.2 \pm 0.5$ & 0 \\
p & $>0.05$ & $>0.05$ & $>0.05$ & $>0.05$ & $>0.05$ \\
\hline
\end{tabular}

\section{DISCUSSION}

The tonsillectomy is one of the most frequently performed surgeries worldwide (1). All surgical techniques have their advantages and disadvantages (4). Bipolar cautery tonsillectomy is a safe operation method (1). An ideal tonsilectomy should be short, intraoperative bleeding and postoperative pain should be minimal and it should allow the patient to return to daily activities in a short time $(4,8)$. Despite the frequency 
of tonsillectomies, the ideal technique has not been found yet (9). The risk of bleeding increases due to vasodilator effect of anesthetic gases. For this reason, short operation time is important in terms of providing the use of less amount of anesthetic drugs and decreasing the morbidity rate in children $(1,10)$. Appropriate and rapid intraoperative bleeding control reduces the operation time. When the studies in the literature were examined, the operation time was observed to be shorter in the cauterization methods when compared to the cold techniques (1). Weimert et al. reported the mean operation time in unilateral tonsillectomy by monopolar cauterization and cold dissection tonsillectomy method to be 2.5 and 6 minutes, respectively (11). In our patients, the mean operation time in bilateral tonsillectomy was determined as 12.3 on average.

Pain after a tonsillectomy is an important problem (12). Pharmacological and surgical approaches are important in reducing pain (2). Cold dissection tonsillectomy is the most commonly used surgical technique in combination with traditional and bipolar cautery method $(4,13)$. Although there is less tissue damage in cold techniques when compared to other electronic methods, the results of studies on this issue are still controversial (2). In some studies, it has been indicated that cold dissection and bipolar cautery dissection are not different in terms of postoperative pain $(11,14-16)$. In other studies, it has been revealed that there is less pain in the cold dissection method $(9,17)$. On the contrary, there is also a study indicating that there is less pain in bipolar cautery dissection (18). For this reason, there is no method that can be said to be certainly more advantageous in terms of postoperative pain. In this study, the Wong-Baker scale was used to evaluate postoperative pain. Previously, this scale was also used in the evaluation of pain after tonsillectomies in children (13).

The use of bipolar cautery is important in terms of reducing intraoperative and postoperative bleeding (1). In some studies, the risk of postoperative bleeding was indicated to be higher in hot methods. On the contrary, there are also studies demonstrating that bipolar cautery method is more effective and safer than cold techniques (13). The most common serious complication after tonsillectomy is late-term bleeding and it is seen in $2-4 \%$ of patients (4). No early- and late-term bleeding was observed in any of our patients. The sample size selected in this study was insufficient to compare bleeding rates between the groups.

The applied diathermic energy dose is calculated in watts (1). In tonsillectomies, the cauterization dose applied is between 6-50 watts for performing surgical procedures and providing hemostasis (19). A high dose of bipolar cautery is especially important in terms of pain, delayed wound healing, changes in the sensitive branches of glossopharyngeal and vagal nerve and tissue damage (20). The tonsillectomy is usually performed due to recurrent tonsillitis, and in recurrent tonsillitis, fibrosis occurs in the tissues, which was true for our patients. In addition, the vascular structures providing nutrition to the tissues are damaged due to the fact that $400-600^{\circ} \mathrm{C}$ energy is applied to the tissues with bipolar cautery (1). In this regard, the British Association of Otorhinolaryngology and Head \&
Neck Surgery has recommended the use of as low energy as possible for dissection and hemostasis during a tonsillectomy (21). It is recommended to use a low energy dose, however, the time when energy is applied is also important because if the time increases, more thermal energy and electrical energy are transferred to the tissues, and as a result, more tissue damage occurs. ${ }^{(1)}$ According to our study, since the use of different energy doses did not differ in terms of postoperative pain and operation time, the dose of energy used should be as low as possible. Results supporting our results have also been found in the study conducted by Hyun Chang and J.Hun Hah (2).

In this study, we compared the bipolar cautery method in terms of pain and operation time according to the applied energy dose. In conclusion, we determined that there was no statistically significant difference in terms of operation time and postoperative pain in tonsillectomies using different energy doses. Therefore, we believe that the dose of energy used should be as low as possible in tonsillectomies performed using bipolar cautery.

Ethics Committee Approval: For this prospectively planned study, approval was obtained from Ataturk University Faculty of Medicine Clinical Research Ethics Committee with number of B.30.2.ATA.0.01.00/58.

Peer Review: Externally peer-reviewed.

Informed Consent: Written consent was obtained from the participants.

Author Contributions: Conception/Design of Study- A.K., F.B.; Data Acquisition- A.K., F.B.; Data Analysis/Interpretation- A.K., F.B., K.K.; Drafting Manuscript- A.K., F.B., K.K.; Critical Revision of ManuscriptA.K., F.B., K.K.; Final Approval and Accountability- A.K., F.B., K.K.

Conflict of Interest: Authors declared no conflict of interest.

Financial Disclosure: Authors declared no financial support.

\section{REFERENCES}

1. Soy FK, Dündar R, Yazici H, Kulduk E, Aslan M, Sakarya EU. Bipolar cautery tonsillectomy using different energy doses: Pain and Bleeding. Int J Pediatr Otorhinolaryngol 2014;78:402-6.

2. Chang $\mathrm{H}, \mathrm{Hah} \mathrm{JH}$. Comparison of post-tonsillectomy pain with two different types of bipolar forceps: Low temperature quantum molecular resonance device versus high temperature conventional electrocautery. Acta Oto-Laryngologica 2012;132:130-3.

3. Arbin L, Enlund M, Knutsson J. Post-tonsillectomy pain after using bipolar diathermy scissors or the harmonic scalpel: a randomised blinded study. Eur Arch Otorhinolaryngol 2017;274:2281-5.

4. Ozkırış M. Comparison of three techniques in pediatric tonsillectomy. Eur Arch Otorhinolaryngol 2012;269:1497-501.

5. Shirley WP, ALW, Wiatrak BJ, Pharyngitis and adenotonsillar disease, in: 6th edition, in: Flint PW, Haughey BH, Niparko JK, Richardson MA, Lund VJ, Robbins KT, Thomas JR (Eds.), Cummings Otolaryngology-Head and Neck Surgery: Head and Neck Surgery, vol. 3, Elsevier Health Sciences, 2010,p.2796.

6. G NA, Evaluation and management of pediatric obstructive sleep apnea, in: 6th edition, in: Flint PW, Haughey BH, Niparko JK, Richardson MA, Lund VJ, Robbins KT, Lesperance MM, Thomas JR (Eds.), Cummings Otolaryngology-Head and Neck Surgery: Head and Neck Surgery, vol. 3, Elsevier Health Sciences, 2015, p.2862. 
7. Wong $\mathrm{DL}$, Baker CM. Pain in children: comparison of assessment scales. Pediatr Nurs 1988;14:9-17.

8. Collison PJ, Weiner R. Harmonic scalpel versus conventional tonsillectomy: a double-blind clinical trial. Ear Nose Throat J 2004;83:707-10.

9. Silveira H, Soares JS, Lima HA. Tonsillectomy: cold dissection versus bipolar electrodissection. Int J Pediatr Otorhinolaryngol 2003;67:345-51.

10. Guida RA, Mattucci KF. Tonsillectomy and adenoidectomy: an inpatient or outpatient procedure? Laryngoscope 1990;100:491-3.

11. Weimert TA, Babyak JW, Richter HJ. Electrodissection tonsillectomy. Arch. Otolaryngol. Head Neck Surg1990;116:186-8.

12. Warnock FF, Lander J. Pain progression, intensity and outcomes following tonsillectomy. Pain 1998;75:37-45.

13. Dadgarnia MH, Aghaei MA, Atighechi S, Behniafard N, Vahidi MR, Meybodian $\mathrm{M}$, et al. The comparison of bleeding and pain after tonsillectomy in bipolar electrocautery vs cold dissection. Int J Pediatr Otorhinolaryngol 2016;89:38-41.

14. Heyden HV, Schäfer E, Jecker P, Gosepath J, Mann WJ. Tonsillectomy technique: bipolar scissors vs raspatory: results of a case control study in 138 patients. HNO 2007;55:684-9.
15. Pang YT. Pediatric tonsillectomy: bipolar electrodissection and dissection/ snare compared. J. Laryngol. Otol 1995;109:733-6.

16. Raut V, Bhat N, Kinsella J, Toner JG, Sinnathuray AR, Stevenson M. Bipolar scissors versus cold dissection tonsillectomy: a prospective, randomized, multi-unit study. Laryngoscope 2001;111:2178-82.

17. Atallah N, Kumar M, Hilali A, Hickey S. Post-operative pain in tonsillectomy: bipolar electrodissection technique vs dissection ligation technique. A double-blind randomized prospective trial. J Laryngol Otol 2000;114:667-70.

18. Kirazli T, Bilgen C, Midilli R, Ogüt F, Uyar M, Kedek A. Bipolar electrodissection tonsillectomy in children. Eur Arch Otorhinolaryngol 2005;262:716-8.

19. Lowe D, Cromwell DA, Lewsey JD, Copley LP, Brown P, Yung M, et al. Diathermy power settings as a risk factor for hemorrhage after tonsillectomy. Otolaryngol. Head Neck Surg 2009;140:23-8.

20. Tosun F. Tonsillektomi Ve Adenoidektomi Komplikasyonları. Turkiye Klinikleri J Surg Med Sci 2005;1:26-9.

21. Interim Guidance on the Use of Diathermy in Tonsillectomy, 2005 Available at: http://www.nice.org.uk (accessed 20.04.05). 